Original Article

\title{
Comparision of efficacy of local administration of contractubex \& corticosteroids for hypertrophic scar in maxillofacial region
}

\author{
M uralee M ohan ${ }^{1}$, B. Rajendra Prasad ${ }^{2}$, S. M. Sharma ${ }^{3}$, Tripthi Shetty ${ }^{4} \&$ Ashay Shah ${ }^{5}$ \\ ${ }^{1}$ Professor, ${ }^{2}$ Principal \& Dean, ${ }^{3}$ Professor \& HOD, ${ }^{4}$ Senior lecturer, ${ }^{5}$ Junior Resident, Department of Oral \& M axillofacial \\ Surgery, A.B. Shetty M emorial Institute of Dental Science, Nitte University, M angalore, Karnataka, India \\ *Corresponding Author : Ashay Shah, Junior Resident, Department of Oral \& Maxillofacial Surgery,A.B. Shetty Memorial Institute of \\ Dental Science, NitteUniversity,M angalore-575018, Karnataka, India. M obile : +919742574146 E-mail : ashay13@gmail.com
}

Received : :02-12-2014

Review Completed : 02-02-2016

Accepted

: 10-08-2016

Keywords : TGF- $\beta$, PDGF,

Glycosaminoglycan

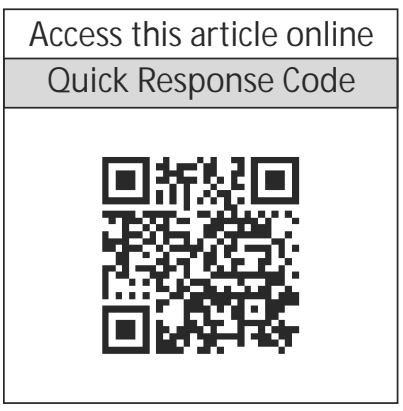

\begin{abstract}
:
Hypertrophic scarring following surgical procedures \& trauma are a great concern for patients and a challenging problem for clinicians. The therapeutic management of hypertrophic scars is a problem that has not yet been satisfactorily solved. Contractubex®ointment and intra lesional injection of corticosteroids have been used effectively for treatment and prevention of hypertrophic scars. However very few data is available to determine the efficacy of Contractubex®ointment and intra lesional injection of corticosteroids for the treatment of hypertrophic scar. Two study groups were made with 10 patients in each group. Patients in Group 1 treated with Contractubex ${ }^{\circledR}$ and patients in Group 2 treated with intra lesional corticosteroid (Triamcinolone acetonide). Scar was analyzed with Vancouver Scar Scale (VSS) at 2 weeks, 6 weeks and 12 weeks. The collected data was statistically analyzed. We found that the difference between before and after treatment scores for each of the groups was statistically significant $(p<0.05)$. The mean of the before and after treatment difference for the Group 1 (Contractubex ${ }^{\circledR}$ ) was 4.7 while that of group 2 (Corticosteroids) was 2.8. This demonstrated a significant superiority of the Contractubex ${ }^{\circledR}$ treatment compared to corticosteroid treatment. The difference between treatment responses for both the groups was statistically significant ( $p$ $<0.05$ ). Excellent to good responses were reported in $90 \%$ of the Group 1 (Contractubex $®$ ) patients and $30 \%$ of Group 2 (Corticosteroids).
\end{abstract}

\section{Introduction}

Peacock defined hypertrophic scarring as a scar raised above the skin level that stays within the confines of the original lesion. ${ }^{1}$ Hypertrophic scars may cause significant functional and cosmetic impairment, symptoms of pruritus and pain, which are all responsible for a dwindling quality of life. ${ }^{2}$ In the developed world four million patients acquire scars and the incidence is even greater in the developing world. Incidence rates vary from $40 \%$ to $94 \%$ following surgery and from $30 \%$ up to $91 \%$ following burns. ${ }^{3}$

Hypertrophic scars develop as the result of a proliferation of dermal tissue following skin injury. They are confined to the original injury and increase in size by pushing outward and not by invasion. ${ }^{1}$ Pathophysiological, hypertrophic scars are characterized by exaggerated extracellular matrix deposition resulting in increased skin tension. ${ }^{2,3}$
The therapeutic management of these scars is a problem that has not yet been satisfactorily solved and includes, e.g., compression therapy, topical/intralesional corticosteroid application, excision, radiation, cryotherapy, laser therapy, interferon therapy, and other therapies directed at a reduction of collagen synthesis. ${ }^{1,3,4}$

Treatment with Contractubex ${ }^{\circledR}[$ Merz Pharmaceuticals, Germany] is reported to be of special value in hypertrophic scars. It is composed of $10 \%$ aqueous onion extract, 50 IU heparin per gram of gel, and 1\% allantoin. Onion extract possesses fibroblast-inhibiting properties. ${ }^{4}$.Heparin induces the formation of thicker fibrils typical of a mature tissue, and also promotes intermolecular bonding in collagen. ${ }^{5}$ Allantoin acts by stimulating the cell mitosis; as well as promoting epithelial stimulation, analgesic action and keratolytic activity. ${ }^{6}$ 
Intralesional corticosteroid injection has also been successfully used. It decreases fibroblast proliferation, collagen synthesis, and glycosaminoglycan synthesis and suppresses pro-inflammatorymediators. ${ }^{7}$

The aim \& objective of the study is to assess \& compare the efficacy of local administration of contractubex®and intralesional injection of corticosteroid inhypertrophic scars of head and neck region, in relation to parameters like pliability, height, pigmentation, vacularity. The purpose of the study is to find out the superiority of the two most commonly used treatment modalities for the hypertrophic scar in maxillofacial region.

\section{Materials \& Methods}

The patients were divided in to two groups with 10 subjects in each group. In group 1 patients were treated with topical application of Contratubex®gel\& in group 2 patients were treated with 1 intra lesional Corticosteroids injection per month. Age group of 15 to 65 was selected. Patients with cosmetically disfiguring post operative scars, hypertrophic scars, traumatic scars in head and neck region were included in the study. Patients with burns, amputations, tendon contractures, cicatricial strictures, hypersensitivity to alkyl 4-hydroxybenzoates (parabens), diabetes, infection were excluded from the study. The subjects undergoing other treatments or having scars older than one year or more were also not considered in the study.

The ethical clearance was obtained from the institute. Written informed consent was taken from all the subjects included in the study. The patients in Group 1 were given contratubex®for topical application. Patient were asked to gently massage the gel for approximately 2 minutes into the skin starting from center to periphery at least twice a day until all gel is absorbed. Patients in group 2 were given one intra-lesionaltriamcinolone acetonide (TAC), injection per month. Injections were given at a dose of $10 \mathrm{mg} / \mathrm{mL}$, injected with a 25- to 27-gauge needle into the upper dermis of a developing hypertrophic scar. Injection was strictly intralesional, identifiable by blanching of the surrounding tissue. Patients were recalled for the followup at the end of $2,4, \& 6$ weeks. Scar development was clinically investigated. Parameters such as pliability, height, vascularity and pigmentation were evaluated by scoring using Vancouver Scar Scale (18), before and after treatment for further validation and for international comparability of the data. ${ }^{8}$

\section{Vancouver scar scale}

\begin{tabular}{|l|l|l|}
\hline Pliability & 0 & Normal \\
\hline & 1 & Supple \\
\hline & 2 & Yeilding \\
\hline & 3 & Firm \\
\hline & 4 & Adherent \\
\hline Height & 0 & Normal \\
\hline & 1 & $1-2 \mathrm{~mm}$ \\
\hline & 2 & $3-4 \mathrm{~mm}$ \\
\hline & 3 & $5-6 \mathrm{~mm}$ \\
\hline & 4 & $>6 \mathrm{~mm}$ \\
\hline Vascularity & 0 & Normal \\
\hline & 1 & Pink \\
\hline & 2 & Red \\
\hline & 3 & Purple \\
\hline Pigmentation & 0 & Normal \\
\hline & 1 & Slightly $\square / \square$ \\
\hline & 2 & Moderately $\square / \square$ \\
\hline & 3 & Severely $\square / \square$ \\
\hline
\end{tabular}

The response to the treatment was rated as excellent, good, minimal, and no response based on the following guidelines. An excellent response was given when the scar scale changed seven or more points after treatment. A good response was given for an improvement of between four and six points.M inimal response was given for an improvement of between one and three points. No response was assigned to those patients who had no change in the Vancouver scar scale.

\section{Statistical Methods}

The data obtained was tabulated and statistically analyzed. The scores obtained at each visit were cross tabulated. Response type $\&$ mean of before and after treatment scores was analyzed using Chi square test and paired t test.

\section{Results}

The parameters pliability, height, vascularity and pigmentation were analysed at the end of $2,4 \& 6$ weeks and the specific score was noted for each parameter for both the groups during each visit and was cross tabulated 
for comparison.Contractubex®was found to be Superior in the normalization of parameters such as height, pliability and pigmentation. The changes seen in height of the scar were most significant, Contractubex ${ }^{\circledR}$ being Superior to corticosteroids ( $p$ value-0.014). Corticosteroid group was found to be more Effective on vascularity parameter of the scar.

The treatment response was statistically significant ( $p$ value-0.017) according to Chi-square test(Table 1 ). Before and after treatment difference in scar scale when compared for both groups was found to be significant ( $p$ value-0.014) (Table-2).

The Contractubex ${ }^{\circledR}$ group was found to be superior compared to the corticosteroids group in normalization of scar parameters.

Table 1 : Comparison of treatment response for both the groups.

\begin{tabular}{|c|c|c|c|c|}
\hline \multirow{2}{*}{$\begin{array}{l}\text { Response } \\
\text { type }\end{array}$} & & \multicolumn{2}{|c|}{ MATERIAL } & \multirow[t]{2}{*}{ Total } \\
\hline & & Contractubex & Corticosteroids & \\
\hline \multirow[t]{3}{*}{ Excellent } & Count & 2 & 0 & 2 \\
\hline & $\begin{array}{l}\% \text { within } \\
\text { response type }\end{array}$ & $100.0 \%$ & $0.0 \%$ & $100.0 \%$ \\
\hline & $\begin{array}{l}\text { \% within } \\
\text { MATERIAL }\end{array}$ & $20.0 \%$ & $0.0 \%$ & $10.0 \%$ \\
\hline \multirow[t]{3}{*}{ Good } & Count & 7 & 3 & 10 \\
\hline & $\begin{array}{l}\% \text { within } \\
\text { response type }\end{array}$ & $70.0 \%$ & $30.0 \%$ & $100.0 \%$ \\
\hline & $\begin{array}{l}\text { \% within } \\
\text { MATERIAL }\end{array}$ & $70.0 \%$ & $30.0 \%$ & $50.0 \%$ \\
\hline \multirow[t]{3}{*}{ M inimal } & Count & 1 & 7 & 8 \\
\hline & $\begin{array}{l}\% \text { within } \\
\text { response type }\end{array}$ & $12.5 \%$ & $87.5 \%$ & $100.0 \%$ \\
\hline & $\begin{array}{l}\text { \% within } \\
\text { MATERIAL }\end{array}$ & $10.0 \%$ & $70.0 \%$ & $40.0 \%$ \\
\hline \multirow[t]{3}{*}{ Total } & Count & 10 & 10 & 20 \\
\hline & $\begin{array}{l}\% \text { within } \\
\text { response type }\end{array}$ & $50.0 \%$ & $50.0 \%$ & $100.0 \%$ \\
\hline & $\begin{array}{l}\text { \% within } \\
\text { MATERIAL }\end{array}$ & $100.0 \%$ & $100.0 \%$ & $100.0 \%$ \\
\hline
\end{tabular}

Graph 1: Bar chart showing the comparison of treatment response for both the groups.

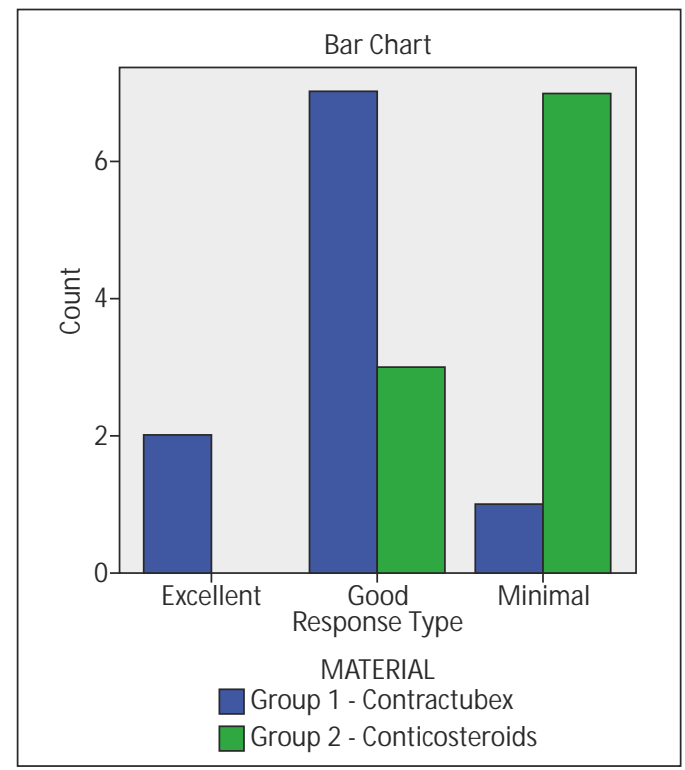

Graph 2: Graph showing the comparison of mean value of difference in pre \& post treatment scores for both the groups.

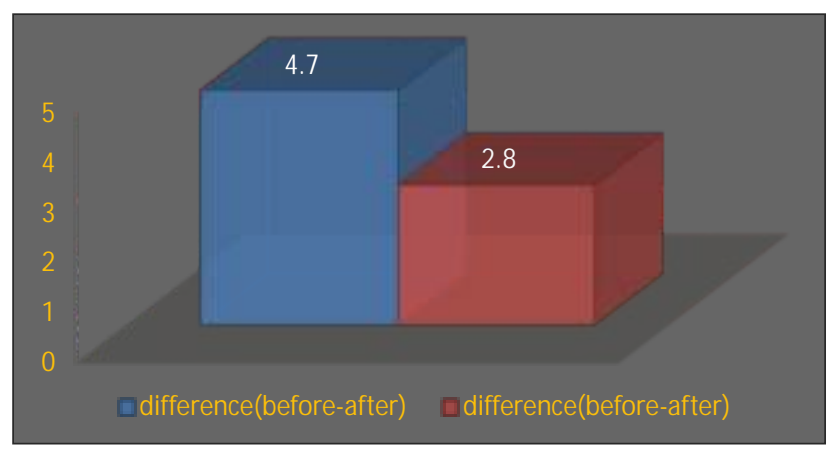

\section{Discussion}

The occurrence of hypertrophic scars has equal sex distribution and the highest incidence in the second to third decade. Incidence rates of hypertrophic scarring vary from $40 \%$ to $70 \%$ following surgery to up to $91 \%$ following burn injury, depending on the depth of the wound. ${ }^{9}$ Scarring usually occurs within 4 to 8 weeks. It has a rapid growth phase for up to 6 months, and then gradually

Table 2 : Comparison (mean \& standard deviation) of total score and pre $\&$ post Treatment score difference at given time interval for both the groups by paired ttest

\begin{tabular}{|l|l|c|c|c|c|c|}
\hline & & Mean & Std. Deviation & $\mathrm{t}$ & $\mathrm{df}$ & Sig. (2-tailed) \\
\hline Total(14) & Contratubex®gel & 7.27 & 2.303 & -1.897 & 58 & 0.063 \\
\hline & corticosteroids & 8.27 & 1.741 & & & \\
\hline $\begin{array}{l}\text { Difference } \\
\text { (before-after) }\end{array}$ & Contratubex®gel & 4.7 & 1.767 & 2.727 & 18 & $\mathbf{0 . 0 1 4}$ \\
\hline & corticosteroids & 2.8 & 1.317 & & & \\
\hline
\end{tabular}


regresses over a period of a few years, eventually leading to flat scars with no further symptoms. Hypertrophic scar is usually linear, following a surgical scar, or popular or nodular, following inflammatory and ulcerating lesions. In the majority of cases, hypertrophic scarring develops in wounds at anatomic locations with high tension, such as shoulders, neck, presternum, knees and ankles. ${ }^{10}$

Hypertrophic scar formation during wound healing is a highly complex genetic process involving disorganized fibrotic deposition of extracellular collagen matrix and inflammatory cell infiltration. There is increased collagen synthesis and reduced collagen degradation. Here, the collagen synthesis is approximately 3 times as great as that in normal unscarred skin. ${ }^{10}$ recent studies investigated the influence of various growth factors in scar. TGF- $ß$ and PDGF have been shown to play an integral role in the formation of hypertrophic scar. The majority of cells involved in wound healing express TGF- $\beta$ in an inactive form that strongly promotes the chemotaxis of fibroblasts to the site of injury. Moreover, this growth factor plays a critical role in fibroblast proliferation and collagen production. When wound repair is completed, the activity of TGF- $\beta$ is normally turned off. However in hypertrophic tissue, TGF- $\beta$ is overproduced and poorly regulated. ${ }^{7}$

Proposed causes for abnormal scar formation have one thing in common which is inflammation.Abnormal scar healing commonly involves areas of high skin tension.Other factors implicated in the etiology of abnormal scar formation include wound infection or anoxia, a prolonged inflammatory response, and wound orientation different from the relaxed skin tension lines. Immunologic alterations have been demonstrated in abnormal scars. Specifically, irregular immunoglobulin and complement levels, increased transforming growth factor beta, and mast cells have been found in abnormal scars. ${ }^{11}$

We found that the difference between before and after treatment scores for each of the groups was statistically significant $(p<0.05)$. The mean difference before and after treatment for the Group 1 (Contractubex $\otimes$ ) was 4.7 while that of group 2 (Corticosteroids) was 2.8. This demonstrated a significant superiority of the Contractubex® treatment compared to corticosteroid treatment. The most affected component of the Vancouver scar scale was height with statistically significant difference $(p<0.05)$, following pigmentation, the most resistant component was pliability for all these treatment methods. Group 1 (Contractubex®) was found to be superior in the normalisation of compared parameters such as height, pliability and pigmentation. Group 2 (Corticosteroids) was found to be more effective in the normalization of vascularity parameter compared to the other group. Complete normalisation of height was seen in $50 \%(n=5)$ of Group 1 patients(Contractubex®) at 12 weeks. In the present study excellent to good responses were reported in $90 \%$ of the Group 1 (Contractubex®) patients and 30\% of Group 2 (Corticosteroids). A study by HuseyinKaragoz et al showed excellent to good responses in $60 \%$ of patients treated with Contractubex $\mathbb{R}^{13}$ A study by J. Beuth et al showed a significant superiority $(p<0.001)$ of Contractubex ${ }^{\circledR}$ treatment as compared to corticosteroid treatment. The time to normalization of erythema, pruritus and consistency was significantly $(p=0.034)$ shorter with Contractubex ${ }^{\circledR}$ treatment than with corticosteroids. $^{12}$

No significant side effects were encountered during the study except for moderate pruritis in two of the patients treated with Contractubex®and mild pruritis was found in one patient treated with corticosteroids. However, the antipruritugenic activity of the corticosteroids is well documented and hence the obvious reason for this finding. ${ }^{12}$ though the efficacy of Contractubex is more compared to corticosteroids, there is a significant difference in the product cost. Contractubex is far more expensive than corticosteroids, which is less effective but cheaper.

\section{Conclusion}

Treatment with local administration of Contractubex was found to be more efficacious $\&$ superior in normalization of scar parameters such as vascularity, pigmentation, height and pliability compared to intra lesional corticosteroids. 
There are many treatment modalities available in literature for the treatment of hypertrophic scar. The therapist should select the most appropriate agent according to the patient's need and guidelines of these signs. Several

\section{References}

1. PeacockJrEE, Madden JW, Trier WC. Biologic basis for the treatment of keloids and hypertrophic scars. South M ed J. 1970;63(7): 755-60.

2. Bock O, Schmid-Ott G, Malewski P, Mrowietz U. Quality of life of patients with keloid and hypertrophic scarring. Arch dermatol Res. 2006; 297(10): 433-38.

3. Leventhal D, Furr M, Reiter D. Treatment of keloids and hypertrophic scars: a meta-analysis and review of the literature. Arch Facial Plast Surg. 2006; 8(6): 362-68.

4. BS, Atiyeh. Nonsurgical management of hypertrophic scars: evidencebased therapies, standard practices, and emerging methods. Aesthetic Plast Surg. 2007; 31(5): 468-492.

5. Ho WS, Ying SY, Chan PC. Use of onion extract, heparin, allantoin gel in prevention of scarring in Chinese patients having laser removal of tattoos: a prospective randomized controlled trial. Dermatology surg. 2006; 32(7): 891-96.

6. Lorena UlhôaAraújol, Andrea Grabe-Guimarãesl, Vanessa Carla Furtado Mosqueiral, Claudia Martins Carneiro. Profile of wound healing process induced by allantoin. ActaCirúrgicaBrasileira. 2010; 25(5): 460-66. comparative studies between these treatment modalities are further required to establish superiority of any one treatment modality over others.

7. Dolores Wolfram, Alexander Tzankov, Petra. Hypertrophic Scars and Keloids:A Review of Their Pathophysiology, Risk Factors, and Therapeutic M anagement. Dermatol Surg. 2009; 35(2): 171-181.

8. Baryza MJ, Baryza GA. The Vancouver Scar Scale: an administration tool and its interrater reliability. J Burn Care Rehabil. 1995; 16(5): $535-$ 8.

9. Lewis W H, Sun KK. Hypertrophic scar: a genetic hypothesis. Burns. 1990; 16(3): 176-78

10. Hans Korting, Tatiana Pavicic, Thomas Ruzicka, Marc Jeschke. Hypertrophic Scarring and Keloids: Pathomechanisms and Current and Emerging Treatment Strategies. M ol M ed. 2011; 17(1-2): 113-25.

11. Cohen IK, McCoy BJ, Mohanakumar T, Diegelmann RF. Immunoglobulin, complement, and histocompatibility antigen studies in keloid patients. PlastReconstr Surg. 1979; 63(5): 689-95.

12. J. Beuth, N. Hunzelmann, R. Van Leendert, R. Basten, M. Noehle and B. Schneider. Safety and Efficacy of Local Administration of Contractubex $\circledast$ to Hypertrophic Scars in Comparison to Corticosteroid Treatment. Results of a Multicenter,Comparative Epidemiological Cohort Study in Germany. IN VIVO. 2006; 20(2): 277-284. 